ERRATUM

Marek Wojciech Kozlowski • Shi Aoxiang

\title{
Ritual behaviors associated with spermatophore transfer in Deuterosminthurus bicinctus (Collembola: Bourletiellidae)
}

Published online: February 17, 2006

\section{J Ethol (2005) DOI 10.1007/s10164-005-0162-6}

The URL in the first paragraph of the Results section is not correct. It should read: http://www.momo-p.com/ showdetail-e.php? movieid=momo040414db01a. 